\title{
Comunicación

\section{Los medios de comunicación en la formación de identidades (trans)nacionales}

JOSÉ CARLOS LOZANO ${ }^{1}$

A pesar de la insistencia en la necesidad de visiones interdisciplinarias y de diálogos entre las diferentes perspectivas sociales y humanísticas críticas que estudian la comunicación y la cultura, es muy raro encontrar obras que realmente lo logren.

Es por eso que el libro editado en inglés y español por los académicos alemanes de la Universidad de Bielefeld, Sebastián Thies, y de la Universidad de Duisburg-Essen, Josef Raab, E Pluribus Unum? National and transnational identities in the Americas / Identidades nacionales y transnacionales en las Américas representa un aporte valioso y novedoso sobre este tema tan emblemático de la región. Con la participación de investigadores europeos, norteamericanos y latinoamericanos trabajando en enfoques teóricos diversos como los estudios culturales, literarios, lingüísticos, musicales y mediáticos, el libro presenta 24 capítulos que abordan el tema de las identidades desde perspectivas multifacéticas y convergentes sobre cine, literatura, música y medios de comunicación.

1 Instituto Tecnológico y de Estudios Superiores de Monterrey. México.

Correo electrónico: jclozano@itesm.mx 
Interesados en la conformación de una perspectiva teórica auténticamente "interamericana" que abreva en las áreas conocidas comúnmente en Norteamérica y Europa como "estudios americanos" (en realidad "estudios sobre Estados Unidos") y "estudios latinoamericanos", los dos editores y un grupo adicional de académicos de diferentes países unen fuerzas para estudiar, de manera interdisciplinaria, los fenómenos de representación, construcción, negociación y hasta instrumentalización de las identidades individuales, regionales, transnacionales y hemisféricas.

El libro es un ejemplo de pensamiento horizontal y pluralista. Además de la ya de por sí novedosa participación, en los diferentes capítulos, de estudiosos europeos, estadounidenses, mexicanos y sudamericanos, alterna capítulos en inglés y en español para evitar el etnocentrismo lingüístico que tiende a hacerse presente cuando se trata de iniciativas de académicos europeos o norteamericanos. De ahí la selección de la Bilingual Press/Editorial Bilingüe, especializada en publicar libros que combinan ambos idiomas.

La obra abre con un capítulo introductorio que establece, de manera clara, un marco conceptual para utilizar el campo de las políticas de identidad como base para el análisis de los procesos de integración cultural y transnacionalización por el que atraviesan los países de América. Parten de la teoría de los campos de Bourdieu, Sebastián Thies y Olaf Kaltmeier para proponer un modelo que identifique y estudie los diversos actores que participan desde distintas posiciones y con diferentes capitales sociales, culturales y económicos en la (re)negociación y (re)construcción de las identidades culturales en los procesos de transnacionalización e integración del hemisferio.

El resto del libro consta de cuatro secciones: 1) políticas de divergencia e integración en las Américas; 2) el rol de los medios y de las industrias culturales en la formación de identidades (trans)nacionales; 3) negociaciones literarias de la identidad, y 4) diversidad cultural, hibridación y nuevas identidades.

En la primera sección, los autores latinoamericanos José Bengoa y Salvador Millaleo, así como los alemanes Christa Wichterich, Olaf Kaltmeier, Christian Büschges y Klaas Dykmann exploran las formas en que se relaciona la construcción de las identidades con procesos 
políticos actuales. Desde la antropología cultural, Bengoa discute las formas de resistencia cultural, en las clases medias y bajas de Chile, al neoliberalismo puesto en boga desde Pinochet y al ensalzamiento a la modernidad y al consumismo. Millaleo, por su parte, explora las políticas de la memoria en Chile y Argentina basadas en juicios oficiales sobre violaciones históricas de los derechos humanos por los regímenes autoritarios, y el impacto de estos procesos jurídicos en la reconstrucción de las identidades políticas de los ciudadanos. Wichterich, desde la perspectiva de género, reconstruye el desarrollo del movimiento internacional de mujeres a partir de los años setenta y hasta su tendencia actual hacia la descentralización, flexibilización y radicalización del movimiento transnacional feminista. Kaltmeier, por otro lado, se centra en ejemplos de discursos y prácticas de comunidades indígenas en Bolivia, Ecuador y Chile en relación con las reformas neoliberales de tercera generación y explica las complejas formas en que estos grupos nativos las resisten y las estrategias gubernamentales para enfrentarlas y emplearlas de manera instrumental. Continuando con el tema indígena, Büschges, desde una perspectiva comparativa y transnacional, estudia las contribuciones de actores, discursos y prácticas étnicas en procesos de inclusión y exclusión política en Los Andes sudamericanos y en el Nepal del sudeste asiático. Cierra esta sección el capítulo de Dykmann, en el que aborda el antagonismo actual en las relaciones interamericanas entre el panamericanismo, que promueve la colaboración comercial entre todos los países del hemisferio americano (incluyendo a Estados Unidos y Canadá), y el bolivarismo que promueve la integración latinoamericana y el distanciamiento de esta región con Estados Unidos.

La segunda sección es aún de mayor interés para los investigadores de la comunicación, pues ofrece diferentes estudios de caso que permiten entender y evaluar el papel crucial de los medios de comunicación en el modelaje y reconfiguración de las identidades colectivas de diferentes países del hemisferio americano. Enrique Sánchez Ruiz, desde la economía política, revisa algunos de los que él llama "mitos" más persistentes en la literatura culturalista contemporánea sobre el posnacionalismo, la actividad de la audiencia, el supuesto escaso impacto de los medios de comunicación debido a los procesos de negociación o mediación de sus contenidos y la supuesta capacidad exportadora de 
América Latina, y lanza un llamado a recuperar una visión crítica y a complejizar y abandonar el esencialismo adjudicado a esos mitos.

El artículo de Libia Villazana, por su parte, discute las medidas del gobierno de Hugo Chávez para reactivar y proteger el cine y la televisión venezolanas, en particular la creación de la Fundación Villa del Cine, que promueve la realización de películas nacionales y que ha financiado la producción de más de 200 documentales de grupos comunitarios, los cambios en la Ley de Cinematografía que establecen cuotas de pantalla, de distribución y de contribución de 5\% de las entradas al fondo para el cine, así como el caso de Telesur, concebida como una CNN latinoamericana. Mostrando la riqueza de perspectivas e intereses de los participantes en el libro, el capítulo de Josef Raab se dedica a analizar los filmes del cineasta chicano Gregory Nava y su recuperación de los latinoestadounidenses como sujetos y no objetos en la cultura norteamericana. En una línea paralela, Chris Lippard comenta la percepción de Estados Unidos en películas de Bolivia como un país materialmente rico pero espiritualmente pobre y emocionalmente vacío. Sebastián Thies, por su parte, estudia el reemplazo de representaciones maniqueas sobre los latinos y la migración por estrategias discursivas más complejas en el cine de Estados Unidos, centrándose en el caso de las películas Traffic, Crash y Babel.

Las tecnologías de la información y la comunicación, dada su relevancia en los actuales procesos de transnacionalización, no podían dejar de abordarse en el libro. Heike Greschke aborda la construcción y reconfiguración de factores como la "comunidad" y la "nacionalidad" a través del uso de Internet en el ámbito transnacional, mediante el caso de un portal cibernético que conecta a paraguayos dispersos en todo el mundo. Steven Loza, por su parte, discute la globalización de la cultura musical latinoamericana y de la industria relacionada con ella, y ofrece una explicación del porqué de su éxito en otras regiones del mundo.

La tercera sección, aunque más enfocada a perspectivas literarias y artísticas, ofrece al estudioso de la comunicación rutas y pistas sobre las conexiones y repercusiones culturales de los fenómenos de globalización y transnacionalización. Los alemanes Jens Martin Gurr y Werner Kummer discuten obras literarias de Luis J. Rodríguez y de Guillermo Cabrera Infante respectivamente. Gabriela Pisarz-Ramírez, por su 
parte, analiza la construcción de identidades "americanas" alternativas en la obra de Juan Felipe Herrera y Rubén Martínez, mientras que el escritor chicano José Limón estudia el trabajo del antropólogo texano Américo Paredes y, desde él, convoca a la conformación y adopción de un enfoque basado en el "regionalismo crítico".

La cuarta y última sección del libro regresa a las discusiones teóricas de fondo sobre los procesos de reconstrucción, reconfiguración y representación de las identidades culturales, pero desde casos concretos. Los capítulos abordan tanto la teorización sobre diversidad cultural e hibridación (Alfonso de Toro), como el mestizaje y las fronteras de género (Luz Angélica Kirschner), el "chicanismo", "rascuachismo" y "diafrasismo" (Alfred Arteaga), el lenguaje, el bilingüismo y la "creolization" como marcas de identidad (Stephen Gramley), así como las identidades rotativas en el mundo contemporáneo (entrevista de Josef Raab a Ilan Stavans, experto en América Latina y cultura latina del Ahmerst College, Estados Unidos).

En un espacio académico latinoamericano de comunicación donde es muy raro encontrar juntas, en una sola obra, ensayos y trabajos desde las perspectivas de los estudios de cine (film studies), de género, chicanos, literarios, culturales y de medios, el libro editado por Thies y Raab es un excelente recordatorio de la necesidad de enfrentar y asumir los retos de interdisciplinariedad y transdisciplinariedad en el campo de la cultura y la identidad. Algo de lo que hablamos mucho pero hacemos muy poco. 
